\title{
REDE URBANA E APONTAMENTOS SOBRE O SISTEMAS DE CIDADES NO URUGUAI
}

\author{
Alberto Silva Cadena ${ }^{1}$
}

Resumo: Desenvolveu-se reflexão sobre a rede urbana como categoria de análise geográfica. Para isso revisitou-se autores consagrados sobre o tema e, como método utilizado, abordou-se a distribuição de serviços e fluxos entre centros urbanos. Realizou-se breve apresentação do quadro urbano e territorial uruguaio, destacando aspectos importantes sobre a organização de sua rede urbana, tais como: a predominância de uma "cabeça de rede" e um cenário de intensa macrocefalia urbana. Para analisar o sistema urbano do país, utilizou-se trabalho desenvolvido por Martínez, Delgado e Altmann (2016), onde identifica-se níveis de associação entre as cidades, estabelecidos pelos fluxos do transporte rodoviário. Considerando a abordagem dos autores, constatou-se evidências sobre possíveis permanências e mudanças na rede urbana uruguaia.

Palavras-chave: Urbanização, Rede urbana, Sistema de cidades, Transporte rodoviário, Uruguai.

\section{THE URBAN NETWORK AND NOTES ON THE SYSTEM OF CITIES IN URUGUAY}

\begin{abstract}
A study of the urban network as a geographic analysis category was developed. For this, prominent authors on the theme were reviewed, and the study of service and flow distributions was chosen for the methodology. Uruguay's urban and territorial situation was briefly presented, emphasizing important aspects of its city network's disposition, such as the prominence of one "flagship city" and an intense urban macrocephaly. In order to analyze the country's urban system, this article refers to research developed by Martínez, Delgado, and Altmann (2016), which identifies the interrelation degree between cities, as established by road transport flows. Based on the authors' approach, evidence of possible changes and continuities in the Uruguayan urban network was found.
\end{abstract}

Keywords: Urbanization, Urban networks, Systems of cities, Road transport, Uruguay.

\section{INTRODUÇÃO}

Neste artigo, será realizada uma reflexão sobre o tema da urbanização, no âmbito do capitalismo em sua fase global, através do qual emergem redes corporativas e técnicas, que por sua vez acabam por conferir novas dimensões nas relações espaço-tempo, bem como reestruturando os territórios, a partir de novos arranjos produtivos e urbanos. Neste sentido, realizamos reflexões conceituais no

\footnotetext{
${ }^{1}$ Doutor e Mestre em Geografia pela Universidade do Estado do Rio de Janeiro (UERJ). Professor da Fundação de Apoio à Escola Técnica (FAETEC) e da Prefeitura Municipal de Macaé (RJ). Email: albertoscadena@gmail.com
} 
campo da geografia urbana, como forma de melhor observar as redes de cidades que se rearticulam, continuamente, nas mais diferentes escalas geográficas.

Buscamos revisitar alguns autores consagrados a respeito da rede urbana enquanto categoria de análise de arranjos espaciais, mas ainda com um percurso traçado considerando parte dos trabalhos que se desenvolveram sobre a urbanização no Uruguai, em especial seu sistema urbano. As considerações a respeito de bibliografia uruguaia, se justifica pela escolha deste país, em pesquisa realizada sobre a relação entre o respectivo mercado varejista de combustíveis, os transportes rodoviários e o sistema urbano nacional.

O conceito de rede representa um dos mais significativos para a Geografia, sobretudo na fase global do capitalismo. Os trabalhos a respeito das redes urbanas têm-se constituído em uma importante abordagem na Geografia Urbana (BESSA, 2012). Entre os trabalhos relativos à organização espacial das redes urbanas, ressalta-se a "teoria das localidades centrais", do geógrafo alemão Walter Christaller. No entanto, é possível considerar que a vanguarda sobre o tema das redes urbanas, representada pelo trabalho de Cristaller, se deve também ao seu esforço em organizar uma série de estudos pré-existentes, a respeito das redes de cidades

[...] foram produzidos estudos que antecederam a tese clássica de Walter Christaller, marco de referência para os estudos sobre redes urbanas. Dentre os principais precursores, estão Richard Cantillon, Jeann Louis Reynaud e León Lalanne, que colocaram em evidência a natureza hierárquica da relação entre os centros urbanos e propuseram uma formulação de hierarquia urbana semelhante à de Christaller... O interesse dos geógrafos pela temática da hierarquia urbana foi despertado, sobretudo, a partir das décadas de 1920 e 1930, a exemplo dos estudos de Robert Dickinson, Hans Bobek, Vaino Auer e do próprio Christaller [...] (BESSA, 2012, p. 149).

Se existe uma noção geral entre os geógrafos contemporâneos de que o tema das redes urbanas não mereceu ainda a atenção necessária, certamente isto não se deve à importância das mesmas no processo de compreensão da realidade sócioespacial, no contexto do meio tecnocientífico informacional. "A localização das atividades e da população assume uma importância crucial, tanto para os capitalistas quanto para o Estado. Dessa importância, emerge... o interesse em compreender a natureza e o significado da rede urbana" (BESSA, 2012). A autora prossegue, ao considerar a fundamental influência do modo de produção capitalista, sobre a organização espacial da produção e das redes urbanas, nos contextos distintos às diversas fases do capitalismo, sobretudo do século XVIII aos dias atuais

[...] o capitalismo recriou as condições de sua existência (rede urbana) [...], visto que, além de pontos fixos, os centros urbanos, no território, exige-se, para a efetiva constituição de uma rede urbana, a existência de uma economia de mercado e de um mínimo de articulação entre esses referidos pontos. Dessa forma, a cidade torna-se o lugar da divisão social e territorial do trabalho. Neste último caso, os centros urbanos passam a ser os elos de ligação na totalidade do espaço, seja em nível regional, nacional ou mesmo internacional. Com o avanço do capitalismo, a atividade comercial ganhou, gradativamente, um novo significado, ampliando o território de atuação e estabelecendo, entre a dimensão da produção e do consumo, a circulação (distribuição e troca de mercadorias produzidas), cujo caráter, na obtenção do lucro, 
passou a desempenhar papel fundamental na sociedade e na organização espacial (BESSA, 2012, p. 152-153).

A reestruturação do capitalismo e a nova Divisão Internacional do Trabalho, com a maior atuação de empresas do "mundo pobre" e emergência das relações do tipo sul-sul, representam o cenário amplo das mudanças nos processos de urbanização, em escalas locais e global. As redes geográficas compõem um poderoso instrumento de apreensão da realidade contemporânea e os estudos recentes privilegiam sua maior instantaneidade aos fenômenos espaciais, principalmente evocados pelo desenvolvimento dos meios de comunicação e transportes, mas que também se aplica à integração produtiva e às redes urbanas (DIAS, 1995).

Atualmente, portanto, observam-se mudanças na conformação das redes urbanas, que fizeram com que alguns pesquisadores sugerissem outras categorias de análise para as relações de centralidade e hierarquia entre centros urbanos. Alguns autores "dessa temática vêm alertando para a redefinição e a complexificação dos papéis dos centros urbanos e, por conseguinte, da própria rede, sugerindo, até mesmo, a existência de redes de redes e de sistemas urbanos" (BESSA, 2012). Entretanto, ainda não é comum encontrarmos tais referências, tanto na literatura brasileira quanto uruguaia.

De acordo com Claudio Egler existe uma importante diferença entre "rede" urbana e o que aparecerá como "sistema" urbano ou de cidades. Tratando da abordagem metodológica para a rede urbana sulamericana, o autor descreveu sua concepção acerca das diferenças entre as categorias "rede" e "sistema"

a noção de rede urbana situa-se em um nível intermediário de abstração e manifesta características históricas e geográficas de um determinado território, como as conexões das redes técnicas de transportes e telecomunicações, que manifestam decisões de investimento tomadas em períodos temporais de média duração. Por fim, reservou-se o termo sistema urbano para os arranjos territoriais moldados em períodos de curta duração, refletindo o comportamento dinâmico dos fluxos materiais e imateriais entre cidades. Estes fluxos manifestam os movimentos conjunturais da economia e seus impactos sociais sobre o emprego e a renda (EGLER, 2015, p. 54).

De acordo com Egler, a categoria "sistema" é de maior proveito na identificação dos níveis de associação que os serviços, as corporações, seu capital fixo, são capazes de estabelecer entre as cidades, em uma escala nacional. Isto em razão da alternância na intensidade e abrangência dos serviços oferecidos, em escalas de análise global-nacional. Entretanto, não encontramos respaldo teórico, além dos mencionados acima, que possam oferecer mais elementos para que se estabeleça diferenças de aplicação das duas categorias que, ainda de acordo com Egler, costumam ser empregadas como sinônimos. Vale lembrar que a literatura uruguaia usa tão somente o termo "sistema", não tendo sido encontrado, em nenhum momento, a palavra red, embora os pesquisadores com os quais mantivemos contato ${ }^{2}$ para nossa pesquisa, compreendam a equivalência do significado da expressão red de ciudads. Portanto, é desta forma que os termos aparecerão no decorrer do texto, como equivalentes.

\footnotetext{
${ }^{2}$ César Ruiz (Universidad Nacional de Colombia); Federika Alvarez, Raquel Alvarado e Juan Hernandez (Universidad de La Republica - Uruguai), entre outros.
} 
Deste modo, se fez necessária uma análise de alguns referenciais teóricos que elucidam o conceito de rede e sua amplitude, onde mais nos interessa os "lugares, que são interligados" (HAESBAERT, 2004). Ainda, a consideração a respeito de proposições que articulem a rede urbana a fluxos rodoviários, fenômeno de serviço realizado à sociedade e utilizado em nossa pesquisa. Tão somente, faremos referência a um trabalho que desenvolve o tema do sistema de cidades no Uruguai, partindo de relações de níveis de associação espacial, observadas a partir de fluxos rodoviários, entre centros urbanos.

As abordagens causais entre o capitalismo contemporâneo e a urbanização, suas relações de implicação, estão relacionadas aos aspectos presentes no esforço de espacialização dos circuitos da economia urbana. Portanto, significa refletir em como o fenômeno urbano impacta a organização do espaço e dos seus "elementos derivados" (o território, a região...). Como poderemos observar, parte dos estudos mais recentes, inclusive a respeito da urbanização no Uruguai, levanta questões sobre o urbano que nos indicam a observar a perspectiva espacial dos fenômenos. Neste sentido, "a rede urbana passou a ser o meio através do qual produção, circulação e consumo se realizam efetivamente. Via rede urbana e a crescente rede de comunicações a ela vinculada, distantes regiões puderam ser articuladas..." (CORRÊA, 1994, p. 5).

A importância das noções de rede se justifica pelo grau que as mesmas nos sugerem de integração. Se a América Latina, seu espaço, se caracteriza por uma tendência histórica ao isolamento geopolítico dos países entre si, sobretudo no caso brasileiro, o estabelecimento e identificação de redes de integração na região podem servir como medida da tendência à reversão do padrão histórico de isolamento. Parte desta aproximação na geografia das redes subcontinentais, se compreende também pela maior exposição que as geografias nacionais podem proporcionar. Por essa razão também, buscamos trabalhos sobre a urbanização uruguaia, país com qual o Brasil mantém relações de proximidade, inclusive geopolítica, em razão da abrangência do Mercosul.

Especificamente sobre a realidade dos países subdesenvolvidos, Milton Santos (1981) abordou sua rede urbana, a partir de traços mais gerais, como o predomínio de "redes lineares ou em espinha de peixe", que denotam a baixa ramificação das mesmas na região. E ainda a respeito da fragilidade das redes urbanas subdesenvolvidas e sua "macrocefalia", Santos considerou que "na escala de um grande país ou de um continente, as redes urbanas encontram-se mal ligadas entre si. Entre zonas de densidade elevadas, aparecem desertos urbanos..." (2008(b), p. 159).

Diante da noção de que as redes urbanas dos países periféricos não existiriam ou estariam "desorganizadas"; Roberto Lobato considerou a relevância de três condições fundamentais e que podem estar dissociadas entre si, para atestarmos a existência das mesmas, quais sejam

primeiramente, haver uma economia de mercado com uma produção que é negociada por outra que não é produzida local ou regionalmente. Esta condição tem como pressuposto um grau mínimo de divisão territorial do trabalho. Em segundo lugar verificar-se a existência de pontos fixos no território onde os negócios acima referidos são realizados, ainda que com certa periodicidade e não de modo contínuo... A terceira condição refere-se ao fato da existência de um mínimo de articulação entre os núcleos anteriormente referidos, articulação que se verifica no âmbito da circulação, etapa necessária 
para que a produção exportada e importada se realize plenamente, atingindo-se os mercados consumidores (LOBATO, 1993, pp. 6-7).

De acordo com o autor, a rede urbana se estabelece a partir da divisão regional do trabalho, onde pontos fixos nos territórios produzem um nível de articulação capaz de fazer sobressaltar as relações de dominação impostas por um conjunto de atividades econômicas. Trata-se de "um conjunto de centros funcionalmente articulados... que reflete e reforça as características sociais e econômicas do território, sendo uma dimensão sócioespacial da sociedade" (CORRÊA, 1993, p. 8). Na realidade uruguaia, uma das formas de se identificar tais relações se dá com o transporte rodoviário nacional.

$\mathrm{Na}$ reflexão sobre o conceito sócioespacial de rede, Marcelo Lopes de Souza considera que as redes geográficas, suas "ligações", "podem se referir a fluxos de vários tipos - de bens materiais, de passageiros, de informação, de energia...-, que articulam e ligam entre si diferentes pontos no espaço geográfico...". O autor, sugere ainda, a utilização de "vias" ou "canais" "não tangíveis", ou imateriais, como no fluxo de informações e pessoas (2013, pp. 165-166).

A rede urbana tem importância decisiva para a dinâmica espacial e, portanto, para o desenvolvimento regional. Uma manifestação concreta da integração territorial de uma determinada região econômica é a consolidação de seu sistema urbano. Pode-se afirmar que o estágio de desenvolvimento e de complexidade da rede urbana manifesta a extensão e a profundidade do processo de integração de uma unidade espacial. Neste sentido, há dois princípios fundamentais em geografia econômica, que estimulam a formação de redes urbanas, a saber, a gestão pública e os investimentos privados (EGLER, 2015).

Existe uma dupla determinação sobre os sistemas de cidades na urbanização contemporânea, considerando sua organização em rede. Primeiro, destaca-se a importância crescente dos fluxos materiais e imateriais entre os centros que estruturam a rede, onde os circuitos financeiros e de serviços especializados assumem funções de protagonismo. Em segundo, não podem ser desprezadas as intensas ligações existentes entre os elos que constituem as cidades-regiões (a exemplo do eixo Montevidéu-Maldonado), ou seja, as interrelações produtivas entre centros urbanos que constituem os aglomerados mais destacados na extensão territorial da rede urbana. Tais determinações constituem-se nos fundamentos das teorias da localização, desenvolvidas na geografia alemã dos anos 30 (sob a influência das escolas de economia e sociologia alemã; Von Thünen, Max Weber, entre outros), cujo aspecto mais destacado está na teoria sobre as localidades centrais, desenvolvida por Christaller em $1933^{3}$, como já mencionado em linhas anteriores.

A teoria dos lugares centrais apresenta a organização espacial das povoações e das áreas de influência, especialmente a sua localização relativa e dimensão territorial. Christaller baseou a sua teoria num conjunto de pressupostos, entre os quais, os "lugares centrais", nos quais a dinâmica da urbanização do espaço mantém relação com a localização, de acordo com suas funções do espaço, para fornecer bens, serviços e funções administrativas a sua área de influência. Alguns lugares centrais acumulam diversas funções e foram denominados, por Christaller, de "centros de ordem superior", na hierarquia das cidades. Outros, fornecendo menor número de funções, são centros de ordem inferior. Desta premissa, pressupõe-se que os centros

${ }^{3}$ Tese de doutoramento intitulada "Os Lugares Centrais no Sul da Alemanha", defendida em 1932 e publicada em 1933. 
de ordem superior cumprem determinadas funções (de ordem superior) que não são oferecidas pelos centros de ordem inferior. Devem cumprir também as funções (de ordem inferior) que são fornecidas pelos centros de ordem mais baixa que a deles (BRADFORD E KENT, 1987).

A importância das relações entre cidades, a partir da escala nacional, foi apontada por Peter Hall (The World Cities, 1966), onde desenvolveu o conceito e explicitou a função das cidades mundiais, na identificação de um "espaço de fluxos" que pode se propagar, para além das fronteiras nacionais. Hall trabalhou com as noções da geografia econômica e urbana, para estabelecer uma relação de supremacia de algumas cidades mundiais, a partir da detenção de determinados requisitos da economia urbana (centros financeiros e bancários, equipamentos urbanos e culturais, entre outros). Embora a análise do trabalho de Hall esteja centrada na importância das cidades, ao mesmo tempo, não se pode pensá-la sem as relações de dominação postas a rede urbana. Daí o sentido da escala a partir do local, mas com vistas de maior amplitude, uma condição essencial na elaboração do conceito e da função das cidades mundiais (EGLER, 2015).

Para análise da rede urbana uruguaia; utilizamos trabalhos de autores (MARTÍNEZ, DELGADO e ALTMANN 2016; LIGRONE, 2017) que consideram a existência de distintos subsistemas urbanos de menor escala. Apoiados sobre a Teoria Geral de Sistemas (TGS) ${ }^{4}$ os autores mencionados lidam com dois tipos de sistemas, complexos e dinâmicos. Especificamente, consideram as abordagens sobre o sistema urbano uruguaio, desenvolvidas desde os anos de 1960, mas com aporte conceitual mais apropriado à realidade das cidades contemporâneas, organizadas em rede, a partir do que Peter Hall chamou de "revolução dos sistemas" (HALL, 1996).

As mediações urbanas são aqui compreendidas como sistemas, basicamente considerando que tais sistemas são abertos, ou seja, se conectam a outros. Considera-se ainda que cada parte do sistema urbano é um subsistema e, portanto, cada sistema urbano pode ser considerado como parte de um sistema mais amplo ou poderoso (BERRY, 1964).

Estas características dos sistemas urbanos contemporâneos, aqui consideradas a partir da TGS, deram impulso a novas perspectivas de análise para outras categorias do urbano, tais como hierarquia e centralidade urbana. As relações de dependência e domínio territorial passaram a ser tratadas como menos lineares e simples, passando às múltiplas escalas de análise. Relações entre centros urbanos deixam de ser consideradas lineares e determinadas por leis gerais, passando a ser consideradas pela dependência recíproca e passíveis de frequentes mudanças.

A noção de rede ou a organização em rede se apresenta como paradigma interpretativo capaz de integrar novas realidades territoriais emergentes, também por articular matrizes teóricas previas, como da hierarquia e centralidade urbana. Camagni (2005), estabeleceu que

As redes urbanas consistem em um conjunto de relações [e dos correspondentes fluxos], que tendem a ser horizontais e não hierárquicos, entre centros urbanos que no modelo clássico não deveriam ter nenhum tipo de relação. Estas relações podem unir entre si cidades diferentemente especializadas e complementares ou cidades similares com uma mesma especialização [...] no primeiro caso teremos redes de complementariedade... e no segundo caso

\footnotetext{
${ }^{4}$ A Teoria Geral de Sistemas foi propagada por autores ligados a Escola de Chicago, a partir da proposição do biólogo Ludwig Bertalanffy e, posteriormente incorporada por autores fundamentais da Geografia Urbana, como Peter Hall, entre outros.
} 
teremos redes de sinergia. Em ambos casos, tem-se uma vantagem específica da organização em rede a respeito da organização hierárquica. No caso das redes de complementariedade, as vantagens para cada centro são as vantagens da especialização. No caso das redes de sinergia, as vantagens estão constituídas pelas chamadas externalidades da rede... (Tradução nossa)

No Uruguai, a rede urbana também pressupõe relações específicas entre as cidades, em razão da natureza da formação histórica do sistema urbano uruguaio, bem como das atividades econômicas e dos fluxos relacionados. Igualmente, pressupõe funções urbanas mais ou menos específicas; dentro do sistema geral que cada país tem, em relação às suas redes urbanas na história.

Tratar do tema da urbanização, em tempos de globalização, implica em considerar seu substrato fundamental, a partir do qual o processo de mundialização, como um todo, tem ocorrido. Tal fundamento diz respeito a um conjunto de técnicas que viabilizam a realização do processo global de desenvolvimento das forças produtivas e dos fluxos pelo espaço mundial. As técnicas impostas aos territórios redirecionam a interpretação do espaço, a partir dos seus fluxos (CASTELLS, 2002).

No Uruguai, articula-se uma rede urbana garantindo uma estrutura econômica e social baseada na circulação rodoviária. A técnica no território concentra-se no urbano, a partir da qual nos sugere as interações na rede urbana uruguaia, materializada pelas próprias técnicas, que por sua vez são também impulsionadas pela realização dos negócios que envolvam os mercados em escala nacional.

A seguir, apresentaremos alguns apontamentos de estudos já realizados sobre a urbanização na América do Sul. Trabalhos e autores que nos serviram de ponto de inflexão e embasamento teórico, para tratarmos do tema da rede urbana na escala do território uruguaio, mais adiante.

\section{ALGUMAS BASES TEÓRICAS A RESPEITO DA URBANIZAÇÃO SULAMERICANA}

Os estudos sobre a urbanização na América do Sul são marcados pela reunião de teorias a respeito da natureza dos processos que a caracterizam. $O$ estabelecimento de redes urbanas na porção espanhola do continente desde o período colonial, o relativo isolamento entre as regiões urbanas, sua macrocefalia e a tendência de formação de redes urbanas; são alguns dos exemplos de desenvolvimento teórico sobre o tema (SINGER, 1973; EGLER 2012).

Sobre o padrão histórico de urbanização na América Latina, Maurício Abreu (1996), tratando da constituição das cidades no período colonial, contrapõe o modelo de urbanização nas Américas portuguesa e espanhola. Apresenta a tese pela qual a colonização espanhola se utilizou de uma estratégia de dominação colonial, sustentada pelas cidades, cuja função urbana era controlar o território e a produção mineral (muito mais intensa do que na colônia portuguesa), na qual a circulação dos metais dependeu muito mais das estruturas urbanas oferecidas pelas cidades, do que as atividades agrárias que predominaram por período significativo da colonização brasileira.

Para a América Espanhola, a rede urbana se desenvolveu já no período anterior à colonização, pela presença de cidades bem estabelecidas entre as civilizações ameríndias desta porção continental e posteriormente, com a chegada dos colonizadores espanhóis, ainda mais, em razão do desenvolvimento da 
"mineração..., o que exigiu uma série de núcleos de controle da produção e circulação dos metais preciosos" (ABREU, 1996, p. 147), principalmente nas áreas andinas.

No entanto, a urbanização periférica, assim como no mundo em desenvolvimento como um todo, se caracteriza pelo baixo grau de modernização dos territórios nacionais. A precariedade de suas infraestruturas territoriais proporcionou uma tendência histórica à aglomeração e menor articulação entre os espaços urbanos, sua "macrocefalia" urbana.

Para Paul Singer, ao tratar da "macrocefalia" urbana na América Latina, a concentração espacial urbana da população, o nível alto de concentração urbana relaciona-se ainda às características da estrutura agrária dos países pobres, com elevada concentração fundiária, onde a população é repelida às cidades. Além disso, considera a modernização parcial do campo, como processo de dispensa em massa de trabalhadores agrícolas. "A acelerada urbanização que se verifica atualmente na América Latina pode ser considerada o resultado da ação conjunta destes fatores" (SINGER, 1973, pp. 70-71). Deste modo, a urbanização no mundo periférico se caracteriza por uma intensa "macrocefalia" urbana, em que as cidades representam aglomerados populacionais, associados à repulsão do campo e à baixa mobilidade espacial dos territórios nacionais, sobretudo se comparados ao mundo desenvolvido.

$\mathrm{Na}$ América Latina, graças às diferenças de impacto das modernizações posteriores à industrialização, as características das cidades, sua capacidade de organizar o espaço e de acumular homens e riquezas..., são diferentes entre os países e no interior de um mesmo país. Tais diferenças referem-se não apenas aos tipos de cidades..., por quanto numa mesma categoria as condições de nascimento e evolução podem variar grandemente, mas num mesmo tipo de cidade os diferentes modelos podem mostrar aptidões variáveis para comandar seu espaço histórico (SANTOS, 1982, p. 58).

Os estudos sobre a urbanização no Uruguai têm se concentrado em dois eixos fundamentais, o crescimento urbano e a temática da metropolização. Os mesmos processos que impulsionaram o crescimento da população urbana a partir dos anos de 1950, com a industrialização, fomentaram o processo de macrocefalia urbana, já descrita por Singer, mas que culminou ainda com a fase da metropolização.

Entretanto, pensar o sistema urbano no Uruguai é algo que se desenvolveu somente nos anos de 1970 e não é uma escala de análise que desperte maior atenção da própria geografia latinoamericana. Mas, "as novas redes urbanas globais podem oferecer oportunidades para a emergência de novos atores, em regiões antes impensadas, com enormes possibilidades para as economias locais..." (PULIDO, 2015, pp. 4-5)

A localização e concentração das atividades econômicas, tem sido um importante agente de reconfiguração dos processos de interação espacial e urbano. Um dos desafios de nossa pesquisa foi também dimensionar as escalas de abrangência destas "interações". Ao que nos pareceu pelo levantamento de dados e bibliografia no Uruguai, foi possível identificar articulações das redes de cidades e a rede de transporte rodoviário nacional.

O processo de pensar o urbano no Uruguai se encontra em um patamar de revisão dos antigos paradigmas de urbanização do território, ainda que alguns modelos urbanos se verifiquem e até com novos impulsos, a exemplo do processo metropolitano. Como ponto de inflexão, optamos por eleger a urbanização uruguaia, que apresenta um processo de metropolização mais evidente, a partir da metrópole 
de Montevidéu, com importante macrocefalia urbana. Estas articulações sugerem uma visita a alguns trabalhos sobre urbanização e rede urbana no Uruguai. Antes, consideramos importante uma breve reconstrução do quadro a respeito da distribuição territorial da urbanização uruguaia.

\section{A DISTRIBUIÇÃO TERRITORIAL DA URBANIZAÇÃO NO URUGUAI}

Desde o período colonial, é marcante o predomínio populacional de Montevidéu, sobre as demais áreas do território uruguaio. Para tanto, deve-se considerar as circunstâncias políticas e econômicas que levaram a capital e, posteriormente sua área metropolitana, a concentrarem cerca de 40,1\% (INE, 2011) da população total do país, com maior densidade populacional (Figura 1). Montevidéu se destacou como cidade portuária desde os tempos coloniais, foi sede administrativa de jurisdição no rio da Prata e base naval espanhola do Atlântico Sul.

Figura 1. Densidade Populacional por Departamento- habitantes por km²

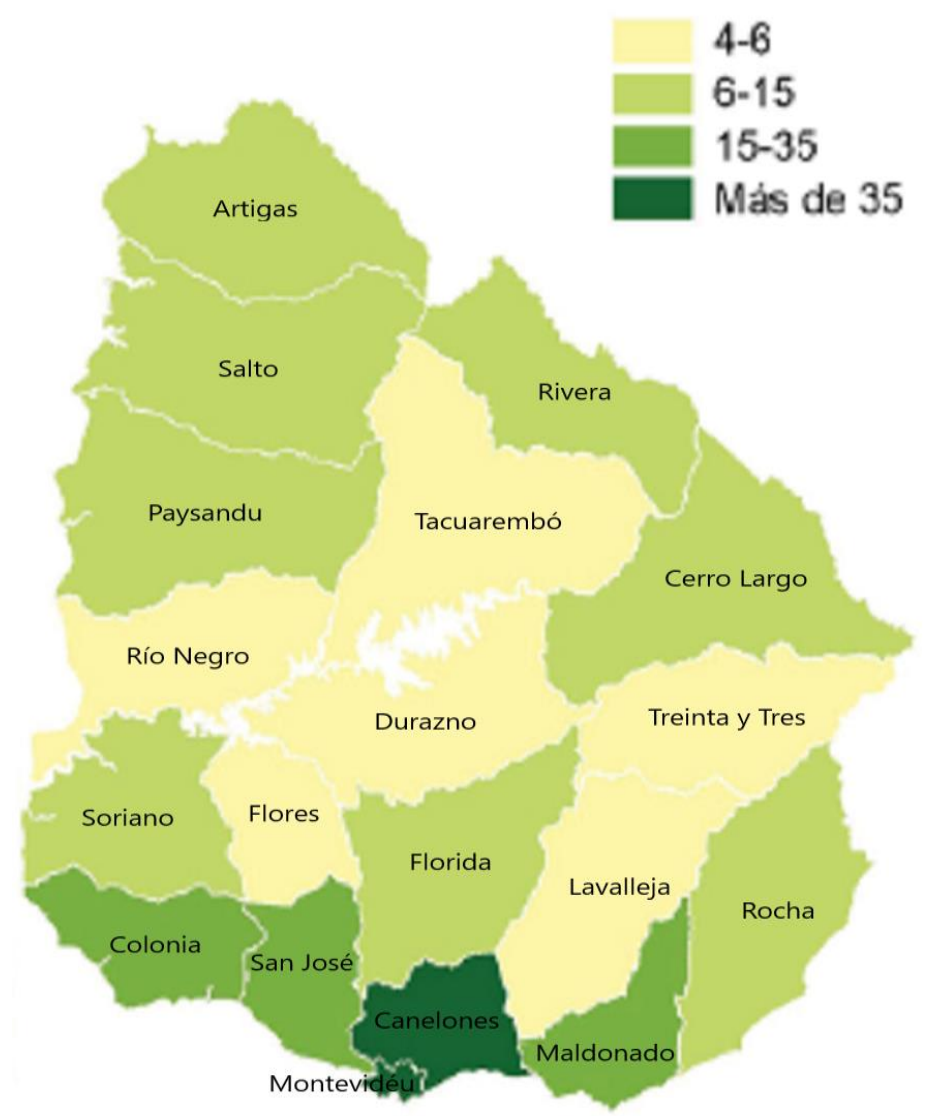

Fonte: Instituto Nacional de Estatística - INE, 2011.

Embora a independência uruguaia e o fim dos litígios territoriais com Argentina e Brasil (Guerra Cisplatina) ${ }^{5}$, no século XIX, tenham contribuído para diminuir a concentração populacional em Montevidéu, permaneceu evidente a hegemonia da capital sobre as demais áreas e cidades do país, culminando com a macrocefalia urbana, já bastante evidente desde a década de 1930.

\footnotetext{
${ }^{5}$ A guerra da Cisplatina foi o conflito ocorrido entre o Império do Brasil e as Províncias Unidas do Rio da Prata, no período de 1825 a 1828, pela posse da Província Cisplatina, a região da atual República Oriental do Uruguai (Rial, 1984).
} 
Há estimativas de que a população uruguaia em 1929 era de 1.684 .915 de habitantes e o censo agropecuário de 1930 indicou uma população rural de 330.000 habitantes, dispersos no território rural. Assim, os aglomerados urbanos somavam em torno de 1.354 .915 de habitantes, o que representava cerca de $80,4 \%$ da população total uruguaia, no período. Ainda que algumas parcelas habitassem povoados e pequenas vilas, já havia claros indícios de esvaziamento do campo, bem como da concentração macrocéfala em Montevidéu (RIAL, 1984). Provavelmente, a capital era a principal receptora desse processo de êxodo rural. Nesse período, apenas o núcleo metropolitano já abrigava cerca de $35 \%$ da população uruguaia (atualmente são $40 \%$, de acordo com o último censo de 2011).

Os centros urbanos além da área metropolitana, especialmente as capitais departamentais, também receberam um número importante de migrantes do campo. Este cenário já contribuía para a construção da noção de um interior vazio, hinterlândias, marcado por pequenos aglomerados de urbanização (Figura 2), em contraposição à macrocefalia em Montevidéu. Metrópole e hinterlândias que caracterizam as marcantes diferenças territoriais que os processos econômicos e políticos produziam ao longo do tempo (RIAL, 1984).

Figura 2. Área e Região Metropolitana de Montevidéu

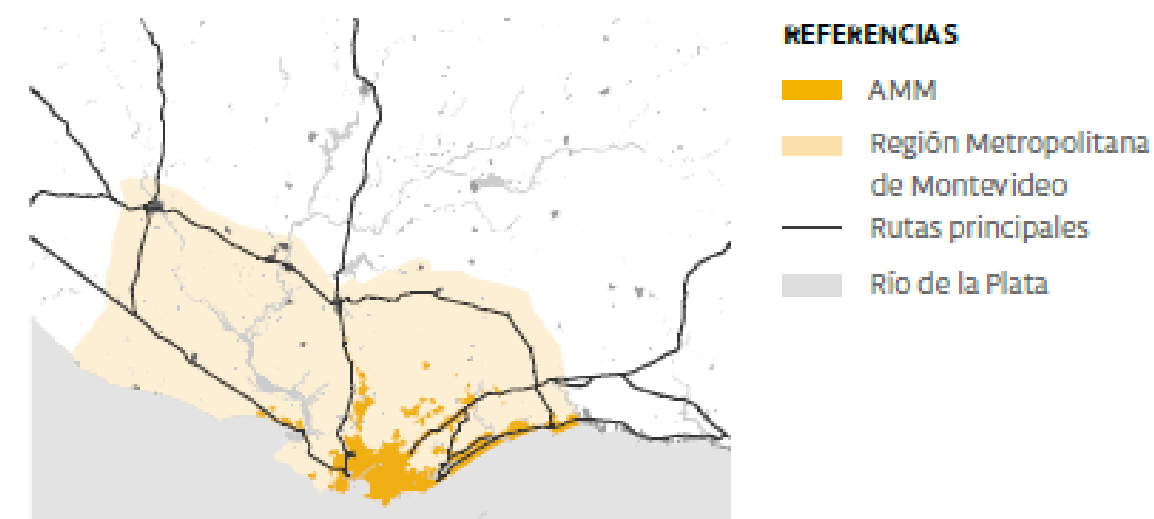

Fonte: Ministerio de Vivienda, Ordenamiento Territorial y Medio Ambiente E Universidad de la República. Facultad de Arquitectura, Diseño y Urbanismo (MARTíNEZ; DELGADO; ALTMANN, 2016).

Na figura 1, é possível notar que, além da densidade populacional mais elevada nos departamentos de Montevidéu e Canelones (dois dos três departamentos metropolitanos e ambos com densidade igual ou superior a 35 habitantes por $\mathrm{km}^{2}$ ), há uma "faixa" (incluindo Montevidéu e Canelones) que se estende pelos departamentos ao sul uruguaio, banhados pelo rio da Prata, que contam com densidade entre $15 \mathrm{e}$ 35 habitantes por $\mathrm{km}^{2}$. São os departamentos de Colonia, San Jose (o terceiro dos três departamentos metropolitanos) e Maldonado.

Os cinco departamentos mencionados dispõem das mais altas densidades populacionais de todo o país, fato que se justifica por um conjunto de aspectos geoeconômicos, produzidos ao longo do tempo. Entre estes aspectos, podemos destacar aqueles relacionados à expansão e modernização das autoestradas uruguaias, que representam eixos de intensificação mais recente da ocupação territorial, a exemplo do turismo nos departamentos de Colonia e Maldonado.

Por outro lado, os departamentos situados na área central do país apresentam as mais baixas densidades populacionais no Uruguai, entre 4 e 6 habitantes por km². 
Trata-se dos departamentos de Río Negro, Durazno, Tacuarembó, Flores, Lavalleja e Treinta y Três. Corresponde a uma área que se estende em uma "faixa" central pelo território uruguaio, de leste a oeste.

Os departamentos compreendidos, apresentaram um histórico de desenvolvimento de atividades agropecuárias extensivas, favorecida nestas imediações do rio Negro, por pastos e recursos hídricos em abundância, mas com baixo emprego da força de trabalho. Este fato não estimulou o surgimento de núcleos urbanos independentes de funções político-administrativas, bem como contribuiu para o baixo crescimento e densidade populacional.

Ademais, quando observamos a densidade populacional no conjunto do território uruguaio, é possível notar que esta aumenta quando nos aproximamos da área costeira do Prata, seguindo pela mesma "faixa" de departamentos com maior densidade populacional. Observa-se ainda, a mais alta densidade populacional que também se estende pela área metropolitana de Montevidéu, em direção ao norte interior.

Deste modo, o processo de produção do território uruguaio, aqui brevemente caracterizado, apresenta uma tendência destacada quanto ao seu sistema urbano, verificada na América Latina como um todo (SINGER, 1973). Tendência representada pela predominância de uma "cabeça de rede" e um cenário de intensa "macrocefalia urbana", traço marcante do sistema de cidades uruguaio.

Contudo, a consagrada noção de que a região metropolitana de Montevidéu segue absoluta na hierarquia urbana uruguaia, pode ser contraposta à ideia de que há pelo menos outra região metropolitana no Uruguai, se não plenamente constituída, mas em processo de formação. Trata-se da Metrópole nucleada por Punta Del Este, no departamento de Maldonado (MARTíNEZ; DELGADO; ALTMANN, 2016). Processo que no Brasil pode ser denominado por "nova metropolização" ou "desmetropolização" (SANTOS, 1993). Em nossa avaliação, uma "metrópole estendida", a partir da região metropolitana de Montevidéu.

O quadro urbano e territorial uruguaio, brevemente apresentado nos parágrafos anteriores, nos oferece aqui apenas uma base (que julgamos importante ao leitor nãouruguaio) para considerarmos a organização do seu sistema urbano. Para este fim, consideramos parte da bibliografia sobre o tema, bem como as interações espaciais proporcionadas pelo transporte rodoviário daquele país. Especificamente, apresentar algumas das abordagens consagradas sobre o meio urbano e a rede de cidades, bem como das perspectivas mais recentes a respeito do quadro urbano do Uruguai.

\section{TRANSPORTE RODOVIÁRIO E O SISTEMA URBANO NO URUGUAI: NOVA METROPOLIZAÇÃO?}

O sistema urbano no Uruguai é marcado por uma hierarquia urbana que apresenta uma grande predominância de seu centro principal, onde Montevidéu se sobrepõe às demais áreas ou departamentos do país, considerando até aqui apenas seu porte demográfico. Esta metodologia pode ser entendida como das mais tradicionais, entre as possibilidades de abordagem de uma rede urbana (CORRÊA, 2006).

De maneira semelhante ao que ocorre em Montevidéu, no interior de cada um dos departamentos uruguaios, "quase todas as unidades administrativas repetem 0 esquema metropolitano. Cada capital departamental, salvo contadas exceções, predomina notoriamente sobre os demais centros urbanos, quando existem" (RIAL, 1984). 
Juan Rial buscou os antecedentes espaciais que conformaram ao Uruguai um território altamente aglomerado em sua área metropolitana principal, nucleada por Montevidéu. O artigo, intitulado "Uruguai, a Gênese de um País Macrocéfalo" (1984), apresenta logo de início a afirmação categórica, a respeito da realidade urbana uruguaia.

Nos poucos quilômetros quadrados que ocupam (os centros urbanos) ou nas áreas de influência delineadas pelos meios de transporte que os unem; há muito tempo que vive a maioria da população, constituindo um país urbano complementado por um campo onde impera um vazio demográfico [...] (RIAL, 1984, p. 1 - tradução nossa).

A configuração do sistema urbano uruguaio é um traço claro do desenvolvimento regional desigual. Os núcleos urbanos hierarquicamente superiores são aqueles que, além da concentração demográfica mais expressiva, dispõem também de maior acesso aos sistemas de comunicação e transporte.

As cidades uruguaias são pontos de uma rede de relações bem mais complexa do que se pode supor, ao tomarmos como noção geral a ideia de que prevalece um sistema urbano repousado sobre uma distribuição espacial, apenas macrocéfala (SINGER, 1973) da sociedade urbana uruguaia. Combinado à monta urbanopopulacional da área metropolitana de Montevidéu, que sem dúvida estrutura a rede urbana uruguaia. Alguns autores (MARTÍNEZ, DELGADO e ALTAMANN 20166; LIGRONE, 2017), consideram a existência de distintos subsistemas urbanos de menor escala.

Importante destacar que a "cabeça de rede" da macrocefalia urbana no Uruguai, Montevidéu, é caracterizada pelos autores em área e região metropolitana. A área metropolitana, ou "conurbano" metropolitano, refere se a um conglomerado (Figura 2) em "forma de ameba esticada sobre tramas de autoestradas de acesso/saída a Montevidéu, que por sua vez contém uma rede de vínculos transversais e um fraco protagonismo sobre entornos rurais produtivos" (2016, tradução nossa).

Por outro lado, a região metropolitana, consiste no conjunto diverso de centros urbanos, sem necessária conexão com seus entornos rurais, "de igual ou superior intensidade com Montevidéu urbano", onde se verificam deslocamentos regulares por motivos de trabalho ou estudo. De acordo com o Instituto de Estatística Nacional do Uruguai, INE, os departamentos que compõe a região metropolitana são Montevidéu, Canelones e San José. Do ponto de vista demográfico, a região metropolitana apresenta elevada concentração populacional em seu núcleo, o departamento de Montevidéu.

A população de Montevidéu representa a maior parte da população metropolitana $(67,7 \%)$ e parte importante da população nacional uruguaia $(40 \%)$, como se pode notar na tabela 1. Por seu turno, a metrópole concentra aproximadamente $60 \%$ da população uruguaia, o que reforça a importância da mesma na concentração populacional do país, constituindo-se em principal aspecto da macrocefalia urbana verificada no padrão urbano de distribuição territorial da

\footnotetext{
${ }^{6}$ Os autores estiveram à frente de um extenso estudo realizado sobre o sistema urbano uruguaio, em uma parceria entre o ministério de Habitação e a Faculdade de Arquitetura e Urbanismo da Universidad de la República. O trabalho tomou como objeto de estudo os centros urbanos do país com mais de 3.000 habitantes e a mobilidade de passageiros entre tais centros urbanos. Os centros urbanos se integram com uma ou inúmeras localidades e foram classificados em três possibilidades: Área metropolitana de Montevidéu (amm, composta por Montevideo urbano mais 78 localidades dos departamentos de San José e Canelones), 43 Cidades Intermédias (CIU) com conglomerados de população superior a 5.000 habitantes e 14 pequenas localidades (PLU) entre 3.000 e 5.000 habitantes.
} 
população. Uma questão que se coloca é se podemos afirmar que há uma "metrópole estendida", a incluir ainda os departamentos de Maldonado e Colonia?

Tabela 1. População da "Metrópole Estendida" de Montevidéu - 2011

\begin{tabular}{l|c|c|c}
\hline Departamento & $\begin{array}{l}\text { População } \\
\text { Absoluta }\end{array}$ & $\begin{array}{l}\text { \% na "Metrópole } \\
\text { Estendida" }\end{array}$ & \% no Uruguai \\
\hline Canelones & 520.187 & 23,2 & 15,8 \\
\hline Montevidéu & 1.319 .108 & 59 & 40,1 \\
\hline San Jose & 108.309 & 4,8 & 3,2 \\
\hline Colonia & 123.203 & 5,5 & 3,7 \\
\hline Maldonado da & 164.300 & 7,3 & 4,9 \\
\hline $\begin{array}{l}\text { Total } \\
\text { "Metrópole } \\
\text { Estendida" }\end{array}$ & 2.235 .107 & 100 & 68 \\
\hline
\end{tabular}

Fonte: Instituto Nacional de Estatística, INE, 2011. ORGANIZADO por Cadena, 2019

Neste aspecto, consideramos ainda o que poderíamos caracterizar como uma extensão metropolitana, a formação de uma extensa faixa litorânea por onde se adensam as populações e cujos limites ultrapassam a região metropolitana. Aqui, incluímos os populosos (para a realidade uruguaia) departamentos nãometropolitanos de Colonia e Maldonado. Trata-se de uma área que compreende parte expressiva da população uruguaia e onde também se concentram os principais fluxos de transporte de passageiros por rodovias.

O recorte espacial de uma "metrópole estendida" é apenas uma iniciativa para este trabalho, não se constituindo em área reconhecida como tal, por órgãos oficiais uruguaios. São encontradas indicações neste sentido apenas em textos acadêmicos (MARTÍNEZ, DELGADO e ALTAMANN 2016; LIGRONE, 2017).

Portanto, o que poderíamos denominar de "metrópole estendida", que inclui à região metropolitana os departamentos de Colonia e Maldonado, totaliza 2.235.107 habitantes, em apenas cinco departamentos. O Uruguai conta com uma população total de 3.286.314 habitantes, distribuídos por dezenove departamentos. Deste modo, a "metrópole estendida " concentra $68 \%$ de toda a população uruguaia, presente em aproximadamente $1 / 4$ dos departamentos, de acordo com o Censo 2011. Trata-se de um espraiamento da metrópole de Montevidéu.

Os níveis de associação dos transportes de passageiros (Figura 3), seus fluxos, formam um sistema de objetos espaciais e serve à análise da rede urbana. Tais níveis de associação devem, contudo, serem ressaltados às funções urbanas cumpridas na rede de cidades pelos departamentos mencionados na área da "metrópole estendida". Algo a que não nos propusemos neste artigo.

Esta abordagem apresenta a importância destes departamentos e alguns de seus núcleos urbanos, a partir de um estudo do sistema de cidades nacional, considerando a variação do fluxo de passageiros em território uruguaio. Este estudo, em um de seus resultados, expõe os níveis de associação, relacionados ao fluxo de passageiros para trabalho, em escala nacional.

A partir desta apreciação, os autores Martínez, Delgado e Altmann (2016) abordam a formação do sistema urbano nacional uruguaio e de seus subsistemas ${ }^{7}$. Trata-se de um importante trabalho institucional, organizado pelo Ministério da Habitação, Ordenamento Territorial e Meio Ambiente e pela Universidade da

\footnotetext{
${ }^{7}$ São sistemas menores ao sistema urbano nacional uruguaio e que fazem parte deste, o constituindo (Martínez, Delgado e Altmann 2016).
} 
República. Neste estudo, os autores tratam do sistema urbano nacional uruguaio, a partir dos fluxos de passageiros nas rodovias uruguaias.

Figura 3. Níveis de Associação - Traslados Regulares por Motivo de Trabalho 2015

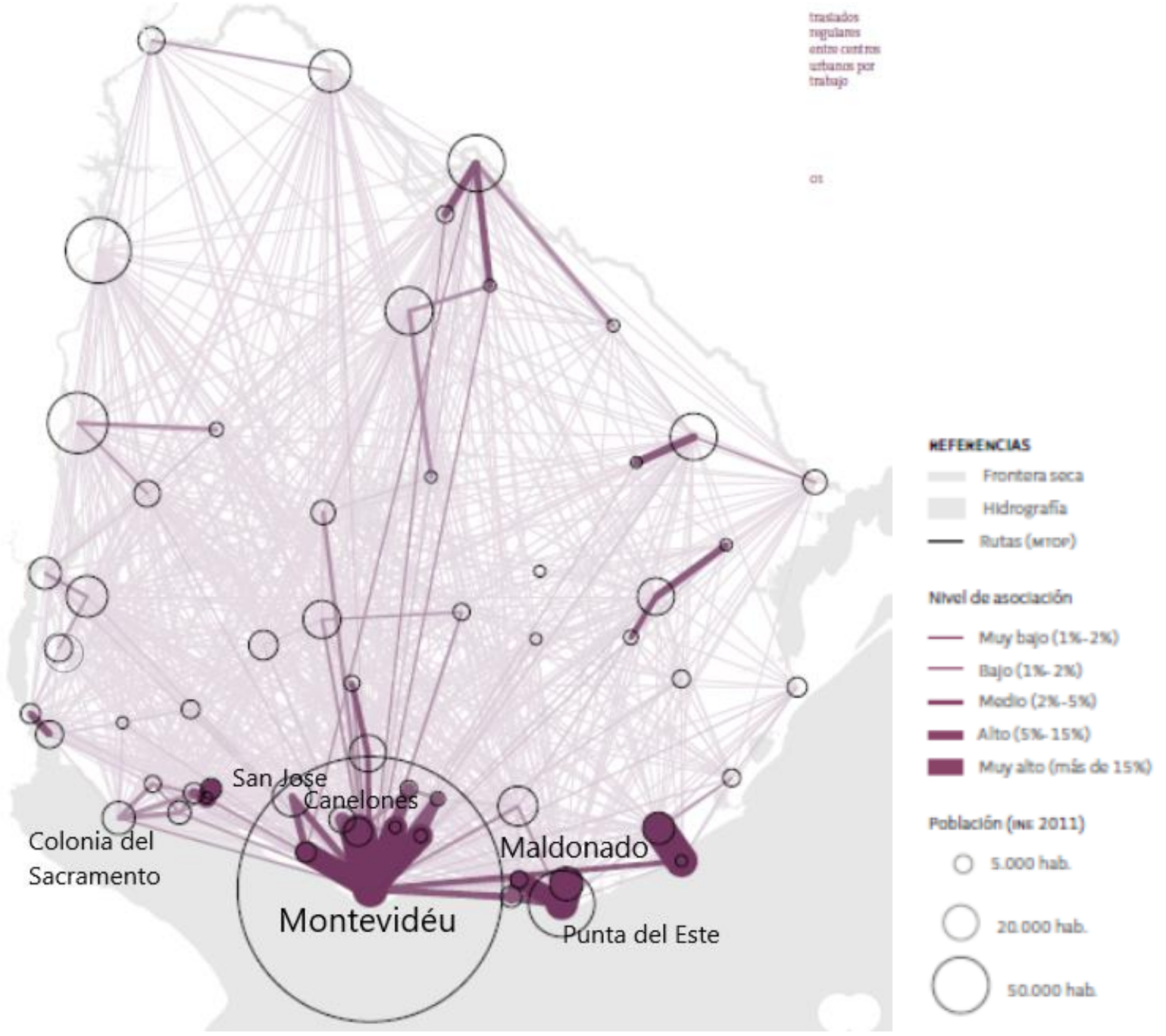

Fonte: Ministerio de Vivienda, Ordenamiento Territorial y Medio Ambiente. Universidad de la República. Facultad de Arquitectura, Diseño y Urbanismo. Martínez, Delgado, Altmann, 2016. Adaptado por Cadena, 2019.

De acordo com a imagem 3, os autores identificaram os níveis de associação alto e muito alto, em todo o território uruguaio, onde é evidente o modelo hierárquico com protagonismo em Montevidéu, sendo a única cidade a polarizar mais de um fluxo de alta e muita alta intensidade. Primeiramente, estabelece estes níveis de associação com algumas capitais departamentais, em espacial Canelones e Maldonado e destas com outras cidades, em escala local. Para o nível médio de associação, também se vislumbra um potencial de alcance nacional, de menor intensidade, de Maldonado/Punta del Este ${ }^{8}$.

De baixa associação, temos os vínculos entre capitais departamentais, o que reforça a polarização exercida por Montevidéu. Colonia del Sacramento e San Jose mantém níveis relativamente baixos de associação com Montevidéu, se

\footnotetext{
${ }^{8}$ Neste artigo, não incluímos as análises quantitativas sobre os níveis de associação entre cidades.
} 
considerarmos que San Jose é uma capital metropolitana e Colonia, uma capital da "metrópole estendida".

De acordo com os autores, a análise da imagem permite concluir que, apesar do sistema urbano manter a característica macrocéfala em Montevidéu, a mobilidade de passageiros permite considerar que outros centros podem se destacar como o que os autores chamam de "subsistemas" menores, identificados a partir dos seus níveis inferiores de circulação de passageiros.

É importante consideramos que a própria macrocefalia urbana no Uruguai não é, pelo menos não mais, uma unanimidade entre aqueles que lidam com rede urbana naquele país (MARTíNEZ, DELGADO; ALTMANN, 2016). O que nós consideramos nesta pesquisa como uma "metrópole estendida" de Montevidéu, incluindo os municípios de Colônia e Maldonado é, na leitura destes autores, a conformação de uma, ou até duas, novas metrópoles no Uruguai. Os autores, ao mesmo tempo, também reforçam o papel central de Montevidéu, mas sugerem um "policentrismo" na costa do Prata:

A costa metropolitana e policêntrica. Se pode dizer que as relações mais complexas e intensas entre cidades associadas a mobilidade por motivo de trabalho se encontra na zona costeira, desde MaldonadoPunta del Este até o par Nueva Palmira e Carmelo (departamento de Colonia) com relações de tipo metropolitanas a leste e de tipo policêntrico a oeste (MARTÍNEZ, DELGADO; ALTMANN, 2016). pp. 95-96 - tradução nossa).

Nueva Palmira e Carmelo são duas cidades, localizadas no litoral noroeste do departamento de Colônia. Estas duas cidades estabelecem fluxos rodoviários mais intensos com a capital departamental, Colônia del Sacramento. Este fato, nos fez repensar o poder de polarização que Montevidéu exerce sobre Colônia, fazendo mesmo diminuir a importância do segundo na "extensão metropolitana" de Montevidéu, estabelecida a oeste da capital uruguaia. Para os referidos autores, mais do que isto, Nueva Palmira e Carmelo mantém relações de interação do tipo metropolitana, em razão dos fluxos rodoviários mantidos entre as duas cidades.

Se os autores não esclarecem qual o status do par Nueva Palmira e Carmelo, quanto à hierarquia regional de cidades, se metropolitanas ou não, entretanto, são mais incisivos ao tratar da metrópole nucleada por Punta del Este. Contudo, trata-se de uma metrópole em processo de formação, o que fica mais ou menos evidente pelos limites impostos na utilização de um único critério, os deslocamentos por motivo de trabalho.

(Sobre) Maldonado-Punta del Este, um espaço metropolitano, assim considerado a partir da leitura sobre a intensidade e o protagonismo das interrelações, dos deslocamentos por motivo de trabalho, entre Maldonado-Punta del Este-San Carlos, e Piriápolis-Pan de Azúcar, tanto observando os pares ou o conjunto, se revela um comportamento que configura este espaço como metropolitano (MARTÍNEZ, DELGADO; ALTMANN, 2016, pp. 95-96 - tradução nossa).

O que para os autores é a formação de uma área metropolitana, para nós, constitui-se em uma "extensão metropolitana", da metrópole nucleada por Montevidéu. E este fato não é menos representativo do processo espacial, para o qual chamamos atenção. Isto é, não vamos nos ater à ordem de grandeza ou a primazia conferida às cidades e aos aglomerados urbanos. Compreendemos que o núcleo metropolitano de Montevidéu tem seu poder de polarização territorial compartilhado 
com outros núcleos urbanos, ainda que a capital siga no topo da hierarquia urbana uruguaia. Montevidéu é um "centro de ordem superior" na concepção de hierarquia urbana de Christaller, pois cumpre funções políticas e econômicas específicas e únicas em escala nacional.

Deste modo, nosso intuito foi destacar a dinâmica territorial e urbana que está em curso. Considerando uma nova metrópole em formação ou uma extensão metropolitana de Montevidéu. Os fluxos rodoviários ainda que signifiquem um elemento apenas, sugerem que há uma dispersão do fenômeno da urbanização no território uruguaio.

\section{CONSIDERAÇÕES FINAIS}

Certa vez, Milton Santos elaborou o capítulo "O Papel das Cidades na Formação das regiões na América Latina", o quarto da obra "Ensaios sobre Urbanização Latinoamericana". Seu objetivo foi de realizar uma interpretação acerca da evolução econômica de Medellín e sua região e os desdobramentos sobre a urbanização local. De modo semelhante, Juan Rial desenvolveu importante teoria a respeito do desenvolvimento urbano no Uruguai (1984). Ambos, há décadas, estavam observando as relações entre as áreas urbanas e a formação regional, como forma de elucidar os processos espaciais que interagem com a organização e o ordenamento dos territórios urbanos.

Algumas concepções estão profundamente arraigadas entre os estudiosos dos temas relativos à ocupação do espaço, a macrocefalia urbana e, a partir daí, o sistema de cidades locais, como expomos na introdução, ainda que brevemente. A apreciação dos níveis de associação e das interações territoriais realizadas para o Uruguai, indicam um cenário local que aponta para algumas mudanças e, ao mesmo tempo, permanências no sistema de cidades.

A respeito da formação de uma "extensão metropolitana", na direção do departamento de Maldonado e ao município de Punta del Este, sentido leste da costa do rio da Prata, observamos fluxos rodoviários são elevados entre Montevidéu - Pan de Azúcar - Punta del Este. No sentido oeste, uma "extensão metropolitana" mais rarefeita, se estabelece em direção ao departamento de Colônia e a sua capital. Se coaduna com os fluxos rodoviários o apontamento para os eixos de expansão metropolitana.

O modelo radial uruguaio reforça a tese da macrocefalia, na concomitância em que sugere uma tendência de dispersão do fenômeno urbano. Ainda que de maneira a não romper, totalmente, com o ciclo de concentração territorial, estabelecido ao longo das margens do Rio da Prata, ao entendermos a "extensão metropolitana" em direção a Punta del Este e a oeste, em direção a Colônia. Com isso, o que Milton Santos denominou de desmetropolização ${ }^{9}$ (1992) - para tratar da fase da "urbanização do território" no Brasil; pode se tornar um processo mais difícil de se verificar no Uruguai, mas parece presente aos autores do estudo que utilizamos. Entretanto, é evidente o limite desta acareação, posto que a teoria da urbanização e das redes urbanas desenvolvida entre estes autores se circunscrevem, em muito, às suas respectivas realidades nacionais.

É, portanto, possível apreender que os territórios nacionais são impactados pela inserção desigual ao sistema capitalista e tendem a experimentar a produção de

\footnotetext{
${ }^{9}$ Milton Santos definiu a desmetrpolização "como a repartição, com outros grandes núcleos, de novos contingentes de população urbana" (1993, p. 16). Significa ainda, a própria dispersão do fenômeno urbano pelo território e os ritmos mais acelerados de crescimento do conjunto das cidades pequenas e médias, se comparados àqueles das metrópoles consolidadas.
} 
um espaço desigual (SMITH, 1988). Os territórios apresentam, deste modo, uma tendência geral ao desequilíbrio, marcada pela concentração espacial dos fenômenos urbano-regionais. Esta tendência é, contudo, mais explícita nos países subdesenvolvidos (SANTOS, 1982) aonde os quadros de desenvolvimento territorial são em muito marcados pela macrocefalia urbana.

Assim, entendemos que a dispersão do fenômeno da urbanização do território, coexiste com o processo que podemos denominar como "acumulação da capacidade de polarização" da metrópole de Montevidéu, em virtude da manutenção e fortalecimento da centralidade montevideana, em concomitância ao aumento da polarização exercida por outros centros urbanos. Os autores que nos referimos, apontam para a tendência de repartição do poder da metrópole nacional uruguaia, com outros centros urbanos, a exemplo de algumas cidades já apontadas.

As cidades intermedias desta região (sudoeste), Colonia, Mercedes e San José, em outro momento enclaves da organização civilizatória de vastos campos, se comportam atualmente como irmãs maiores com certas acumulações e funções específicas de comando estatal (LIGRONE, 2017, p. 315).

Estas cidades compõem um extenso aglomerado urbano, descontínuo, que se estende linearmente pela costa do rio da Prata, com algumas extensões em direção ao interior, sobretudo oportunizadas pelas rodovias radiais a Montevidéu. Esta área, para qual chamamos atenção em relação ao desenvolvimento de uma "policentralidade", foi denominada, em 2006, de Ciudad Celeste. A noção se refere a uma nova entidade territorial no Uruguai, em uma área em que não se tem "uma cidade convencional... (mas sim) um agregado de centros urbanos, de espaços rurais e 'rurbanos' (LIGRONE, 2017, p. 316). A Ciudad Celeste, uma noção ainda pouco difundida, pelo menos na literatura estrangeira à uruguaia, pode materializar o que apontamos como sendo o processo de "nova metropolização" no Uruguai. Este processo é observado a partir de uma "desconcentração concentrada", na costa do rio da Prata.

Nosso argumento reforçou uma tendência, observada por outros autores além dos recorridos aqui, de que o espraiamento da urbanização pelo território, ainda que sua dispersão seja relativa a cada caso, geralmente, tem sido acompanhado pela "acumulação da capacidade de polarização" pelas metrópoles nacionais e núcleos metropolitanos. Não é nosso propósito, mas é importante estabelecer paralelo com o que ocorre, a partir da elevação da cidade de São Paulo ao posto de metrópole global e aos processos urbanos e econômicos relacionados a este fato.

Este artigo não teve por meta estabelecer conclusões fechadas a respeito das transformações na rede de cidades do Uruguai e as reflexões teóricas sobre rede urbana. Contudo, nos parecem importantes as relações possíveis de serem estabelecidas, no sentido de se apontar para a dinâmica espacial uruguaia, considerando as relações espaciais dos níveis de associação dos fluxos em rede, bem como das relações verticais, em uma rede urbana em transformação. 


\section{REFERÊNCIAS BIBLIOGRÁFICAS}

ABREU, Maurício de Almeida. Pensando a cidade no Brasil do passado. In: CASTRO, Iná E.; GOMES, Paulo C. da C., CORRÊA, Roberto L. (Org.). Questões atuais da reorganização do território. Rio de Janeiro: Bertrand Brasil, 1996.

BRADFORD M. G. e KENT W. A. Geografia Humana: teorias e suas aplicações. Editora Gradiva. Lisboa, 1987.

BERRY, Brian, Geographic Perspectives on Urban Systems. Estados Unidos, Prentice Hall, 1970.

BESSA, Kelly. Estudos sobre a rede urbana: os precursores da teoria das localidades centrais. GeoTextos, vol. 8, n. 1, jul. 2012. pp. 147-165.

CADENA, Alberto $S$. "As redes urbanas de Uruguai e Colômbia e a atuação da Petrobrás: fluxos e fixos do transporte nacional, do comércio de combustíveis e a articulação aos sistemas de cidades locais". Tese (Doutorado em Geografia). Universidade do Estado do Rio de Janeiro, 2019.

CAMAGNI, R. EI Principio de Jerarquía (o del orden de las ciudades). Economía Urbana, Espanha, Antoni Bosch Editores, 2005.

CAPEL, Horacio. La Cosmópolis y la Ciudad. Barcelona: Ediciones del Serbal, 2003.

CASTELLS, Manuel. La Questión Urbana. México: Siglo Veintiuno, 1978.

CORRÊA, Roberto Lobato. A Rede Urbana. Editora Ática. São Paulo, 1994.

. Região e Organização Espacial. Editora Ática. São

$\overline{\text { Paulo }} \overline{2007 .}$

. Estudos Sobre a Rede Urbana. Bertrand Brasil. Rio de

Janeiro, 2006.

. Trajetórias Geográficas. Bertrand Brasil. Rio de Janeiro,

2014.

DIAS, Leila Christina. Redes: emergência e organização. In: CASTRO, I. E.; CORRÊA, R. L.; GOMES, P. C. C. (Orgs.) Geografia: conceitos e temas. Rio de Janeiro: Bertrand Brasil. 1995.

EGLER, Claudio A.G., Nodalidade e rede de Cidades na América do Sul. Revista Franco-brasileira de Geografia, 2012. Disponível em:

http://confins.revues.org/7878?lang=pt\#tocto1n1

Referenciais Básicos para uma Metodologia de Identificação do Sistema Urbano da América do Sul. In: Rede Urbana e Integração Produtiva no Brasil e na América do Sul. Relatório de Pesquisa. IPEA, Rio de janeiro, 2015. 
HAESBAERT, Rogério. 0 Mito da Desterritorialização: do fim dos territórios à multiterritorialidade. Bertrand Brasil, Rio de Janeiro, 2004.

HALL, Peter G. The Worl Cities. McGraw-Hill, Nova lorque, 1966.

Serbal. Espanha, 1996.

La Ciudad de la Teoría, Ciudades del Mañana. Ediciones del

Instituto Nacional de Estatística Uruguay, INE. Censos 2011. https://www.ine.gub.uy/censos-2011. Último acesso em: 16 abr. 2021.

LIGRONE, Pablo. Ciudades Medias e Intermedias en Uruguay en un Nuevo Ciclo descentralizador. In: Maturana, F., Sposito, M.E.B., Bellet, C., Henríquez, C., Arenas, F. Sistemas Urbanos y Ciudades Medias en Iberoamérica. Serie GEOlibros № 26, Santiago, 2017.

MARTÍNEZ, E.J., Delgado, M. Y., Altmann, L., Sistema Urbano Nacional: una caracterización con base en la movilidad de pasajeros. Ministerio de Vivienda, Ordenamiento Territorial y Medio Ambiente. Universidad de la República. Facultad de Arquitectura, Diseño y Urbanismo. Montevidéu, 2016.

MENEZES, Eduardo Frigolleto de. A Urbanização em Países Subdesenvolvidos. Em: http://www.frigoletto.com.br/GeoUrb/urbpsubd.htm Acesso em: jan. 2019

PULIDO, Nubis. Globalizacion y nuevas configuraciones urbanas en America Latina. In: Anais do XI Encontro de Geógrafos da América Latina. Havana, 2015, CDRom.

RIAL, Juan, Uruguay. A Gênese de um País Urbano Macrocefalico. Revista EURE, $\mathrm{n}^{\circ}$ 31. Montevidéu, 1984.

SANTANA, Paola Verri. Internacionalização de Empresas Brasileiras e a Entrada de Cidades na Rede. In: PACHECO, Susana Mara Miranda; MACHADO, Mônica Sampaio. (Orgs.) Globalização, políticas públicas e reestruturação territorial. Rio de Janeiro, 7 Letras, 2012.

SANTOS, Milton. A Urbanização Brasileira. São Paulo, Edusp, 1993.

. Por uma outra Globalização: do pensamento único à consciência universal. Rio de Janeiro, Record, 2000.

. Por Uma Geografia Nova. 6ª edição. São Paulo, Edusp, 2004.

edição, São Paulo, 2007.

Ensaios Sobre a Urbanização Latinoamericana. Edusp, $2^{\mathrm{a}}$

A Natureza do Espaço. Edusp, São Paulo, 2008a.

. Manual de Geografia Urbana. São Paulo: EDUSP, $2008 \mathrm{~b}$. 
SINGER, Paul. Economia Política da Urbanização. Editora Brasiliense, São Paulo, 1973.

SMITH, Neil. Desenvolvimento Desigual: natureza, capital e a produção do espaço. Rio de Janeiro: Bertrand Brasil, 1988.

SOUZA, Marcelo L. Os Conceitos Fundamentais da Pesquisa Sócioespacial. Bertrand Brasil, Rio de Janeiro, 2013. 